\title{
Transparência das informações das universidades federais: estudo dos relatórios de gestão à luz dos princípios de governança
}

\author{
Luzia Zorzal \\ Universidade Federal do Espírito Santo - UFES, Brasil. \\ Georgete Medleg Rodrigues \\ Universidade de Brasília - UnB, Brasil.
}

ARTICLE

\begin{abstract}
Resumo
Este artigo baseia-se numa pesquisa de doutorado em Ciência da Informação a qual analisa em que medida os Relatórios de Gestão das Universidades Federais atendem aos princípios de governança estabelecidos para o setor público, segundo diretrizes nacionais e internacionais. Trata-se de investigação de natureza exploratória, descritiva e qualitativa cuja interpretação dos dados ancorou-se na análise de conteúdo. Tem como universo as 63 universidades federais brasileiras, das quais foram selecionadas as que estavam no topo do Ranking Webometrics, em cada uma das cinco regiões geográficas. Os resultados apontaram que, das cinco universidades analisadas, nenhuma atingiu o patamar de alta transparência. Duas universidades classificaram-se no nível médio-alto e três no nível médio-baixo. $\mathrm{O}$ atendimento aos princípios de boa governança nos Relatórios de Gestão dessas universidades ainda é insuficiente para se atingir o nível mais alto de transparência. Os dados evidenciam que, para melhorar esse perfil, é preciso implantar as práticas de boa governança, visando a ampliar a transparência ativa prevista na lei brasileira de acesso à informação. Para tanto, a divulgação das informações necessita ser tempestiva, com clareza e acurácia. Tal iniciativa poderia mitigar a assimetria informacional e democratizar as relações entre Estado e cidadãos.
\end{abstract}

Palavras-chave

Transparência ; Governança ; Universidades federais ; Relatórios de gestão ; Setor público

Transparency of information of federal universities: study of management reports in light of governance principles

\begin{abstract}
This article is based on a doctoral research in Information Science which examines to what extent Management Reports of Federal Universities meet the governance principles established for the public sector, according to national and international guidelines. It is exploratory, descriptive, qualitative research whose interpretation of the data it is anchored on content analysis. It has as universe the 63 Brazilian federal universities, of which those that were ranked at the top of Ranking Webometrics, in each of the five geographic regions were selected. Results show that the five analyzed universities do not reach a high transparency level. Two universities ranked in the medium-high level and three in medium-low level. The compliance with principles of good governance on the Management Reports of these universities is still insufficient to achieve the highest level of transparency. The data show that to improve this profile to increase the active transparency under Brazilian law on access to information and the dissemination of information needs to be timely, with clarity and accuracy implanting good governance practices is necessary. Such initiative could mitigate informational asymmetry and democratize the relationship between State and citizens.
\end{abstract}

Keywords

Transparency ; Governance ; Federal universities ; Management reports ; Public Sector 


\section{Introdução}

A transparência e o acesso à informação pública estão previstos como direitos do cidadão e deveres do Estado na Constituição Federal (CF) de 1988 (BRASIL, 1988) e em outras legislações. A disponibilização transparente das informações é um dos mecanismos que garantem a promoção desses direitos, fortalecem a democracia, ampliam o exercício da cidadania, ajudam a promover o controle social, entre outros.

Horizontalidade, transparência, fluidez, flexibilidade, autonomia dos atores, civismo: esses elementos que se teceram em torno do paradigma doravante central da empresa como proprietária do critério de iniciativa e de desempenho se baseiam, eles também, na crença no poder das tecnologias informacionais [...] para revolucionar totalmente as relações sociais (MATTELART, 2002, p. 153).

As instituições públicas e privadas estão passando por grandes transformações em virtude da dinâmica desses processos. Mudanças decorrentes da revolução tecnológica, por sua vez, refletem no Estado, no governo e na sociedade, provocando conflitos e a exigência de uma atuação mais ampla do governo, não apenas voltada para a eficiência, mas, sobretudo, para a equidade, a justiça social, o desenvolvimento sustentável, a promoção do desenvolvimento humano e o combate à pobreza e à corrupção. Esse cenário requer que o Estado atue de forma transparente na busca de resultados efetivos (MATIAS-PEREIRA, 2010a).

Embora a evidenciação da informação em instituições privadas venha sendo objeto de estudo, isso não ocorre quando se trata das instituições públicas, especialmente das universidades federais (UFs), onde a divulgação da gestão é ainda muito limitada, apesar da sua importância social e do recebimento de significativos recursos públicos.

A transparência poderá ajudar a promover uma Administração Pública mais aberta à participação social e a colaborar na transição da cultura do segredo para a cultura de acesso à informação, com disponibilização proativa de dados e informações. É possível inferir importantes contribuições e estímulos por parte de organismos multilaterais, com destaques para a Organisation for Economic Co-operation and Development (OECD), a International Federation of Accountants (Ifac), o International Monetary Fund (IMF), o World Bank (Banco Mundial), entre outros e, no caso do Brasil, o Tribunal de Contas da União (TCU), o Instituto Brasileiro de Governança Corporativa (IBGC), por exemplo, com a finalidade de incentivar a boa governança mundial e, em consequência, obter mais transparência nas informações.

Uma das formas de se ter acesso às informações das UFs é por meio de seus Relatórios de Gestão (RGs). O TCU instituiu o RG pela Resolução TCU n² 206/1980 (BRASIL, 1980), todavia ele passou a ser exigido das autarquias e fundações, da administração indireta, a partir de 1994 (BRASIL, 1994). Registra-se que a exigência do RG como peça que integra a prestação de contas pelas entidades mantidas pelo poder público federal, está esculpida na Lei no 8.443/1992 (BRASIL, 1992). No entanto, foi pela Instrução Normativa (IN) TCU n 63/2010 (BRASIL, 2010), que se regulamentou a forma de organização e de apresentação dos RGs da Administração Pública Federal (APF) a serem disponibilizados a partir de 2010.

Nesse sentido, objetiva-se analisar em que medida os RGs das UFs atendem aos princípios de boa governança estabelecidos para a APF de acordo com as diretrizes nacionais e internacionais. A informação sob a tutela do Estado é um bem público e sua evidenciação deve ser por iniciativa da Administração Pública, de forma espontânea, proativa, independente de qualquer solicitação, ou seja, transparência ativa, como definido em lei. Cabe, desse modo, às instituições públicas identificar aquilo que é mais demandado pela sociedade e disponibilizar proativamente na Internet e/ou outros meios, a fim de facilitar que os stakeholders encontrem essa informação evitando custos para ambas as partes. Conforme salientou Matias-Pereira (2010b), a transparência é um dos princípios fundamentais das entidades do setor público.

Tanto no Brasil quanto em outros países, os estudos sobre a variação de quantidade de informação revelada pelas entidades do setor privado têm sido explanados sob diversos prismas. Para o âmbito do setor público e especificamente para o setor educacional, esse tipo de estudo é bem mais reduzido. Em países como o Canadá (NELSON; BANKS; FISHER, 2003), Espanha (GALLEGO; GARCÍA; RODRÍGUEZ, 2009), Estados Unidos da América (EUA) (GORDON et al., 2002), México (MALDONADO-RADILLO, 2013) e Reino Unido (GRAY, HASLAM, 1990), apenas para citar alguns, foram identificados estudos que analisaram o segmento universitário.

Por outro lado, no Brasil, para esse setor, existem poucos estudos. Quando se trata de Instituições de Ensino Superior, as pesquisas também ainda são limitadas e tem-se, como exemplos, os trabalhos de Lima (2009) e Polizel e Steinberg (2013). 
$\mathrm{Na}$ busca de estudos a respeito da transparência das informações institucionais das UFs, verificou-se também que as pesquisas ainda são muito restritas. No entanto, algumas foram encontradas no âmbito universitário: Platt Neto, Cruz e Vieira (2004), Pessoa (2013) e Rodrigues (2013).

A limitação é ainda maior quando se analisam os RGs. Como exemplos, tem-se: Bizerra (2011) e Bairral e Silva (2013). Com relação a estudos de RGs de UFs, foi localizado o trabalho de Silva, Vasconcelos e Silva (2013). No entanto, estudos sobre a transparência dos RGs das UFs ainda não foram localizados.

\section{Referencial teórico}

Muitas seriam as teorias e variáveis que poderiam explicar a razão do distanciamento entre as promessas de um governo aberto (GA) e transparente na gestão pública e o que efetivamente acontece na prática. Talvez a razão principal da distância esteja na própria natureza da relação de seus atores - Estado e cidadãos - e na questão agente-principal implícita nesse relacionamento, pois, quando não alinhada, essa relação tende a ser conflitante e pode gerar problemas na condução da boa governança dos contratos.

Com a finalidade de se alcançar o objetivo desta pesquisa, este tópico está organizado em quatro seções, abordando os seguintes temas: teoria do agente-principal, governo aberto, transparência e governança.

\subsection{Teoria do agente principal}

A teoria do agente-principal, geralmente denominada teoria da agência, preocupa-se principalmente com o problema agente versus (vs) principal, também cunhado na literatura como conflitos de agência que se relacionam com os princípios fundamentais sintetizados por Klein (1983), que afirma que não há contrato completo, e por Jensen e Meckling (1976) para quem não há agente perfeito. Em outras palavras, para eles, existe uma relação estabelecida como um contrato sob o qual uma ou mais pessoas (o principal) contratam outra pessoa (o agente) para desempenhar algum serviço ou trabalho em nome dos contratantes, abrangendo a delegação de autoridade para a tomada de decisões pelo agente. Afirmaram que o problema existe em todos os tipos de organizações, inclusive em universidades.

Com base na teoria desenvolvida, os gestores (agentes) contratados tenderiam a agir de forma a maximizar seus próprios benefícios (maior estabilidade no emprego, mais poder etc.), agindo em interesse próprio e não segundo os interesses da instituição e demais partes interessadas (principais). Para reduzir o problema, Jensen e Meckling (1976) sugeriram que as instituições deveriam adotar uma série de medidas para alinhar os interesses dos envolvidos, objetivando, principalmente, o sucesso da organização. Para tanto, foram estabelecidas medidas que incluíam práticas de monitoramento, controle e ampla divulgação de informações. A esse conjunto de práticas convencionou-se denominar governança.

Os debates relacionados com a governança possuem suas raízes históricas no desenvolvimento teórico ocorrido em economia na chamada teoria da firma, base da teoria do agente-principal. Vários estudos foram desenvolvidos, no século XX, sobre a teoria da firma: Coase (1937), Alchian e Demsetz (1972), Ross (1973), entre outros. Pela teoria da firma, a empresa é percebida como um conjunto de contratos estabelecidos entre os seus integrantes (acionistas, fornecedores, clientes, governo etc.). Cada integrante colabora com a firma e recebe algo em troca. Desse modo, como afirma Marques (2007, p. 13), a governança corporativa "[...] é um conjunto de regras que visam minimizar os problemas de agência".

De forma análoga, no setor público, a relação entre gestor (o agente) e eleitor, ou seja, o cidadão (o principal), poderá ser caracterizada como uma relação de agência (ROSS, 1973; SLOMSKI et al., 2008). Também se pode considerar que os cidadãos são o principal e os políticos, seu agente. Os burocratas, por sua vez, são agentes de seu principal, os políticos, e, indiretamente, dos cidadãos (OSZLAK; KAUFMAN, 2014).

A transposição da teoria do agente-principal para o setor público também é proposta por Rossetti e Andrade (2012), colocando o contribuinte como principal e os gestores públicos como agentes para o modelo de governança pública.

As questões contempladas pela teoria agente-principal estão relacionadas com a existência de informação assimétrica entre agente-principal. A assimetria ocorre quando uma das partes (agente) possui mais informação em detrimento da outra parte (principal). Esse fenômeno acontece porque o agente tende a estar mais 
diretamente vinculado às operações diárias da instituição do que o principal, além de outros fatores próprios da dinâmica das sociedades contemporâneas.

Stiglitz (2002) explica que há uma assimetria natural de informações entre os que governam e os que são governados muito parecida com a assimetria informacional existente entre os gestores das empresas e seus acionistas.

A assimetria de informações nas instituições públicas está associada ao fato, aparentemente simples, de governantes e seus auxiliares deterem uma série de dados e registros que não estão à disposição dos governados (CANELA; NASCIMENTO, 2009).

Em sociedades democráticas, cidadãos têm o direito básico de saber, de se expressarem, de serem informados sobre o que o governo está fazendo, sobre as motivações e também debater o assunto. Essas sociedades pressupõem a transparência e abertura por parte dos governos. No entanto, reconhece-se que, em proveito próprio, governos e seus líderes não incentivam o disclosure ${ }^{1}$ e, consequentemente, a disseminação de informações contrárias a seus interesses, assinala Stiglitz (2002).

A teoria do agente-principal vista aqui brevemente servirá de pano de fundo para os próximos tópicos, notadamente a governança.

\subsection{Governo aberto}

A ideia de GA ganhou destaque nos últimos anos e tem se posicionado como a nova promessa que propiciará reinventar a gestão pública e expandir as capacidades de ação da cidadania, refletindo a transição de um modelo analógico, hermético e autorreferente nas anacrônicas burocracias públicas, para alcançar um modelo digital, aberto, participativo e inclusivo (GÜEMES; RAMÍREZ-ALUJAS, 2012).

No relacionamento entre Estado e cidadania, a abertura é uma das modalidades que contribuem para a redução de sua opacidade. Possibilita a participação cidadã nos assuntos públicos, o que provoca a centralidade do cidadão nos aspectos participativos da democracia. O governo de diversos países tem desenvolvido iniciativas direcionadas a incrementar a abertura, a transparência e a colaboração entre o Estado e os cidadãos, aproveitando-se dos avanços das Tecnologias de Informação e Comunicação (TICs).

O GA é uma dessas iniciativas. É definido, por Oszlak e Kaufman (2014), como uma relação de mão dupla entre cidadania e Estado, possibilitada pela disponibilidade e aplicação de Tecnologias de Informação e de Conhecimento, que facilitam múltiplas interações entre atores sociais e estatais e se traduzem em vínculos mais transparentes, participativos e colaborativos.

Oszlak e Kaufman (2014) admitem que GA e governo eletrônico (GE) sejam conceitos polissêmicos, cuja conotação possibilita diferentes significados e alcances. Sua complexidade aumenta quando se observam outros termos, como: governo 2.0, e-democracia, ou open data (dados abertos), surgidos para se referirem a esses mesmos conceitos ou a alguns de seus conteúdos. Às vezes se sobrepõem. A polêmica entre os dois termos parece bastante ampla. As definições assumem significados diferentes, dependendo do país. Outra questão é que os conceitos evoluem rapidamente, principalmente na área de TIC.

Dados abertos e GA também são termos que carregam ambiguidade e um pode existir sem o outro. Um governo pode ser aberto e, nesse sentido, ser transparente, mesmo se não adotar novas tecnologias. Um governo pode fornecer dados abertos sobre temas "politicamente neutros" e mesmo assim continuar profundamente opaco e irresponsável (YU; ROBINSON, 2012, p. 196).

Dados abertos são dados que qualquer pessoa pode usar livremente, reutilizá-los e redistribuí-los, estando sujeito, no máximo, à exigência de creditar a sua autoria e compartilhar pela mesma licença (OPEN KNOWLEDGE FOUNDATION, 2012).

Oszlak e Kaufman (2014) definem GE, citando o Banco Mundial, como aquele que usa tecnologias de informação capazes de transformar sua relação com cidadãos, empresas e outros ramos do governo e podem servir a uma variedade de fins: melhor produção de serviços governamentais; uma interação mais fluida com a empresa privada; maior empoderamento do cidadão por meio do acesso à informação ou um desempenho governamental mais eficiente. Os benefícios resultantes podem traduzir-se em menor corrupção, maior transparência, maior conveniência para o usuário, crescimento da arrecadação e/ou redução de custos. 
O Centro Latinoamericano de Administración para el Desarollo (Clad), por meio da carta ibero-americana de GE aprovada pela IX Conferência Ibero-Americana de Ministros de Administração Pública e Reforma do Estado, definiu GE como:

[...] o uso das TICs nos órgãos da Administração para melhorar a informação e os serviços oferecidos aos cidadãos, orientar a eficácia e eficiência da gestão pública e incrementar substantivamente a transparência do setor público e a participação dos cidadãos (CLAD, 2007, p. 7, tradução nossa).

Recorrendo-se a outras fontes, a OECD (2010), por exemplo, definiu GA como a transparência de ações do governo, a acessibilidade a seus serviços e informações e a receptividade do governo para novas ideias, demandas e necessidades. Ainda de acordo com a OECD, existem três princípios-chave a serem levados em consideração: accountability, ${ }^{2}$ transparência e participação social.

Um GA conta necessariamente com o auxílio da informática e, por outro lado, um GE poderá não ser necessariamente aberto. Considerando que a eletrônica é um auxiliar imprescindível de um GA, o GE seria um componente indispensável do primeiro. Dizendo de outro modo, o GA seria o fim e o GE o meio ou um dos meios. Isso não significa que um seja subalterno ao outro. Ambos se propõem melhorar o desempenho do setor público, simplificar sua gestão e facilitar a vinculação entre Estado e cidadania. Uma distinção fundamental é que, enquanto o GE almeja um desempenho tecnológico eficaz da gestão estatal, o GA realiza tímidos avanços para a instauração de um modelo de organização social em que a velha matriz Estado-central está se deslocando, potencialmente, para uma matriz sociocentral (OSZLAK; KAUFMAN, 2014).

López (2013, p. 2, tradução nossa) sustenta que "[...] o governo aberto transcende o governo eletrônico em um aspecto crucial: enquanto o governo eletrônico é uma questão de gestão, o governo aberto é uma questão de poder. Mas, ainda que o transcenda, necessariamente o inclui".

Essa tendência de abertura, sob o ponto de vista político, segundo Machado (2015), está relacionada com a publicação da Declaração de Budapeste (14-2-2002) e com a Declaração de Berlim (22-10-2003), que estabeleceram, em nível mundial, as bases ao movimento acesso aberto.

A declaração do Presidente dos EUA, Barack Obama, realizada em 2009, logo após assumir seu primeiro mandato, quando anunciou a decisão de converter seu governo em um GA, reforçou esse movimento, elencando três princípios fundamentais do GA: transparência (saber), participação (tomar parte) e colaboração (contribuir) (OBAMA, 2009).

Posteriormente, em 20 de novembro de 2011, foi constituída a Open Government Partnership (OGP), em que oito países fundadores da parceria (África do Sul, Brasil, EUA, Filipinas, Indonésia, México, Noruega e Reino Unido) assinaram a Declaração de GA e apresentaram seus Planos de Ação (OSZLAK; KAUFMAN, 2014). Em setembro de 2015, integravam a OGP, 66 países-membros. Os países-membros têm o compromisso de seguir os quatro princípios básicos definidos pela OGP, quais sejam:
a) transparência;
b) participação cidadã;
c) accountability; e
d) tecnologia e inovação.

No Brasil, essa iniciativa deu-se com o Decreto Presidencial, de 15 de setembro de 2011, que instituiu o Plano de Ação Nacional sobre GA, destinado a promover ações e medidas que visem ao incremento da transparência e do acesso à informação pública, à melhoria na prestação de serviços públicos e eficiência administrativa e ao fortalecimento da integridade pública.

O GA torna-se importante pelos valores que os circundam, tais como: abertura, transparência, ética, participação, colaboração, controle social, democracia, entre outros. A combinação desses valores poderá contribuir para melhorar as relações Estado-sociedade. Resta saber se esses valores constantes dos planos de ação apresentados pelos países-membros do OGP estão sendo efetivamente implementados. 


\subsection{Transparência}

O termo transparência assumiu novos significados e ganhou popularidade nas duas últimas décadas, com a disseminação das boas práticas de governança corporativa que têm relação sobre o modo como as empresas são administradas e controladas. Após os anos 1970, a transparência ocupou lugar de destaque no discurso administrativo na América do Norte e na Europa ocidental. Tornou-se, então, um dos valores essenciais da Administração Pública, configurando-se como um eixo privilegiado do reformismo administrativo que fez da transparência o princípio, e do segredo a exceção (JARDIM, 1999; RODRIGUES, 2013).

Com base em pesquisa da literatura, Michener e Bersch (2011) concluíram que o primeiro estudo a fazer uso da palavra transparência, com o sentido atual, data de 1962, quando o economista dinamarquês Knud Erik Svendsen a utilizou em conexão com o problema de transparência em macroeconomia.

Rodrigues (2013, p. 424) argumenta que, na atualidade, "[...] a noção de transparência já está incorporada embora não inteiramente praticada pelos governos e instituições - como uma premissa para o bom funcionamento da Administração Pública".

$\mathrm{Na}$ literatura, encontram-se diversas definições para o termo transparência, com variados graus de especificidades, dependendo do contexto. A argumentação de Michener e Bersch (2011), ao exporem acerca da conceitualização da qualidade da transparência, está centrada em duas dimensões que a circundam: visibilidade e inferabilidade, que representam o grau no qual a informação é completa e facilmente localizada (visível), e o nível no qual a informação é útil e verificável (inferível).

Na concepção de Scholtes (2012), existem várias perspectivas, pois é um conceito que compreende muitas áreas e diferentes contextos: acesso público, legitimidade, participação, boa governança, confiança, accountability, comunicação, privacidade, poder, entre outros. Scholtes (2012) considera transparência um conceito ambíguo, e não simples. Essa ambiguidade e multiplicidade a tornam uma ferramenta valiosa e popular no vocabulário dos políticos que querem convencer as pessoas de suas opiniões e que o cidadão acredite que os interesses da sociedade estão mais bem protegidos por eles. Isso decorre da característica de conotação positiva que tem a transparência. Com relação ao conteúdo, não é um fenômeno inocente. No que diz respeito às suas intenções, a transparência esclarece, explica, torna acessível e fornece orientação. Ao mesmo tempo, a informação que tem sido feita transparente também é seletiva e exclusiva e poderá enfatizar uma coisa em detrimento de outra.

Schnackenberg e Tomlinson (2014) tentaram sintetizar definições de transparência para compor suas definições. Realizaram uma pesquisa, no período entre 1990-2009, e apresentaram, por áreas de domínios do estudo, os autores e suas respectivas definições para o termo transparência. Após verificarem as sobreposições e discutir as conceitualizações similares, sustentam que a transparência não é unidimensional, e sim composta de três dimensões específicas: disclosure, clareza e acurácia. Suas análises evidenciam que a maioria das aplicações gerencialmente relevantes da transparência existe no nível organizacional, especificamente no relacionamento organização vs stakeholders. Definem transparência como a qualidade percebida de informação intencionalmente compartilhada de um emissor, e enfatizam que transparência é uma função do disclosure, clareza e acurácia da informação.

Para uma melhor compreensão da abordagem de Schnackenberg e Tomlinson (2014), apresenta-se a seguir a definição que utilizaram para as três dimensões:

- Disclosure - definido como a percepção de que a informação relevante é recebida tempestivamente. Na literatura, uma variedade de estudos advoga para o uso do disclosure como uma dimensão central da transparência. Disclosure implica informação compartilhada abertamente para ser considerada transparente;

- Clareza - definida como o nível percebido de lucidez e compreensibilidade da informação recebida de um emissor. Sugerem que a informação deve ser simples o suficiente para ser facilmente compreendida;

- Acurácia - definida como a percepção de que a informação é correta na medida do possível, dada a relação entre emissor e receptor. 
Cada uma dessas dimensões contribui exclusivamente para o nível global de transparência, aumentando a confiança dos stakeholders na qualidade da informação recebida da organização. Isto é, como os stakeholders percebem a informação: a) mais relevante e oportuna - disclosure é aumentado; b) mais compreensível clareza é aumentada; c) mais confiável - acurácia é aumentada. A representação das três dimensões da transparência - disclosure, clareza e acurácia - é descrita no modelo conceitual apresentado por Schnackenberg (2009) por meio da Figura 1.

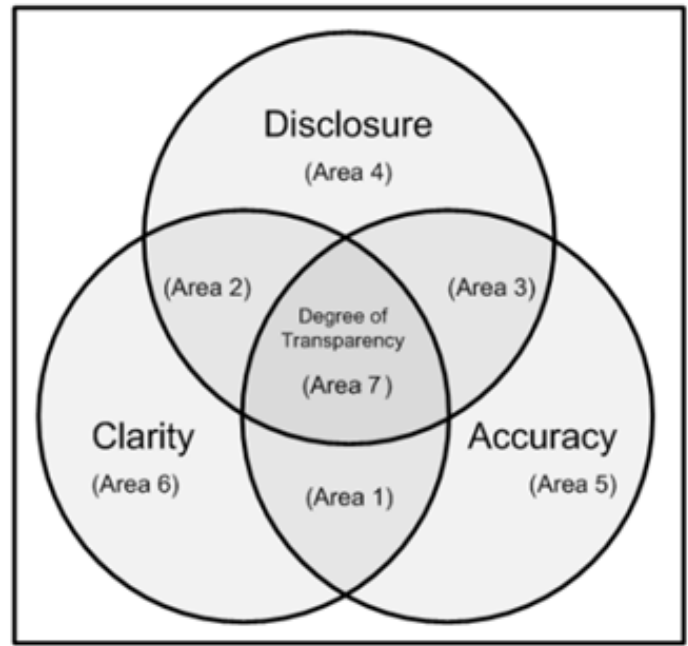

Figura 1 - Modelo conceitual de transparência Fonte: Adaptado de Schnackenberg (2009, p. 14)

Inferências para as interações duplas da Figura 1: a área 1 indica informação clara e precisa mas que ainda não foi publicada, provavelmente não será percebida pelos stakeholders; a área 2 representa informação divulgada com clareza, porém imprecisa e pode conduzir os stakeholders a fazerem inferências potencialmente prejudiciais; a área 3 do modelo representa informação divulgada, precisa, entretanto não é claramente apresentada ou é evidenciada num jargão que não tem significado para os stakeholders ou, então, não lhes é familiar ou de difícil compreensão.

Inferências do anel externo da Figura 1: a área 4 mostra informação amplamente divulgada (fully disclosed) mas que não é nem clara nem precisa, portanto, de pouco valor; a área 5 indica que a informação que é ao mesmo tempo não divulgada e não clara é inútil, mesmo que seja precisa; a área 6 expõe a informação que apresenta clareza, mas que não possui precisão e não foi divulgada para as partes interessadas; a área 7 mostra que, quando as representações são divulgadas de forma clara e precisa, a informação nela contida pode ser considerada contendo um forte grau de transparência. No entanto, o autor alerta que, como as representações são necessariamente limitadas (Ex.: disponibilidade de tempo limitado, capacidade imperfeita do ser humano de ler os requisitos de receptores de informação), representações puramente transparentes, indiscutivelmente, não existem.

Segundo a Transparency International (2009, p. 44, tradução nossa), "[...] a transparência é a qualidade de um governo, empresa, organização ou pessoa de ser aberta na divulgação de informações, normas, planos, processos e ações". E os funcionários têm a obrigação de atuar de maneira visível, previsível e compreensível na promoção da participação social e na prestação de contas, ou seja, na promoção da accountability.

Fox (2007) afirma que os conceitos de transparência e accountability estão inerentemente relacionados, são bastante maleáveis e envolvem quatro argumentos:

a) diferentes metas de accountability: individual vs institucional;

b) problema de controle de qualidade da informação oficial;

c) distinção conceitual entre os dois tipos de transparência: clara e opaca;

d) tipo de accountability: suave ou rigorosa. 
Além da suposição de que a transparência pode limitar o abuso do poder, ela pode ter diferentes metas. Algumas são destinadas a inibir a corrupção, outras tentam encorajar um desempenho institucional melhorado. Diferentes metas implicam diferentes estratégias. As primeiras, mais legalistas, tendem a focar as características individuais e a revelar os detalhes, enquanto as últimas atuam mais nos impactos dos gastos públicos (FOX, 2007).

O segundo aspecto envolve a diferença entre dados oficiais relevantes e informações confiáveis. Está relacionado com os tipos de disclosure: voluntário e obrigatório. Para Fox (2007), o voluntário parece ser intrinsicamente limitado, dada a tendência de se esconder informações prejudiciais.

Com relação aos dois tipos de transparência - clara e opaca -, Fox (2007) afirma que transparência clara se refere a ambos: a) política de acesso à informação; e b) programas que revelam informações confiáveis sobre o desempenho institucional especificando responsabilidades das autoridades assim como onde os fundos públicos são gastos. Transparência opaca, ou difusa, envolve a disseminação de informação que não revela na verdade como as instituições se comportam na prática, seja com relação à forma como os gestores tomam decisões, seja com referência aos resultados de suas ações. O termo refere-se também à informação que é divulgada, mas não é confiável.

Como último aspecto distingue a accountability em duas dimensões: suave e rigorosa. A suave seria a responsabilização, enquanto a rigorosa inclui responsabilização com sanções, compensações e/ou indenizações.

Fox (2007) sustenta que a transparência não necessariamente conduz à accountability e vice-versa. Ele destaca que a transparência é necessária, mas longe de ser suficiente para produzir accountability. Esse autor classifica ainda a transparência em duas categorias: proativa e demand-driven (acesso passivo). Disseminação proativa refere-se à informação que o governo torna pública sobre suas atividades e seu desempenho, e acesso passivo reporta-se ao compromisso institucional para responder às solicitações dos cidadãos para tipos específicos de informação ou documento, do contrário, não seria possível acessá-los.

Com relação à disseminação proativa e ao acesso passivo, o Decreto $n^{\circ}$ 7.724, de 16 de maio de 2012 (BRASIL, 2012), que regulamentou a Lei de Acesso à Informação (LAI), também utiliza essas abordagens: transparência ativa - quando a Administração Pública divulga informações à sociedade por iniciativa própria, de forma voluntária, independente de qualquer solicitação; e transparência passiva - quando divulga informações sob demanda, em atendimento às solicitações dos stakeholders.

A transparência é apenas um dos princípios fundamentais para a boa governança nas entidades e a gestão tem que estar preocupada com todos os princípios. Apenas por fatores limitativos, haja vista o foco do presente estudo, a ênfase está em transparência. Para se alcançar a transparência, diversos organismos sugerem o mecanismo da governança cujos aspectos serão detalhados na seção seguinte.

\subsection{Governança no setor público}

A gestão pública tem suas complexidades e especificidades que a distinguem das organizações privadas, exigindo habilidades e conhecimentos específicos. A questão da democracia e seus aperfeiçoamentos não se separam da gestão pública, obrigando-se a incentivar a participação dos stakeholders e tornar suas ações transparentes e submetidas a um efetivo controle social (NOGUEIRA, 1998).

Ao contextualizar o setor público, a International Federation of Accountants (Ifac) destaca que é um setor complexo, suas entidades não operam dentro de uma estrutura legislativa comum nem possuem forma e tamanho organizacional padrão (IFAC, 2001). É importante, portanto, reconhecer a diversidade do setor público e os diferentes modelos de governança que se aplicam em vários países e em diversos setores. Cada qual tem características únicas que requerem atenção especial e impõem diferentes conjuntos de responsabilidades.

Embora o termo governança date de idades remotas, o conceito e a importância que atualmente Ihe são atribuídos foram construídos nas últimas três décadas, inicialmente nas organizações privadas. No entanto, recentemente, tem recebido atenção em todos os setores e em nível mundial. As entidades governamentais operam em um contexto diferente e são, portanto, confrontadas com outras questões. Contudo, a natureza dos problemas é semelhante (NETHERLANDS, 2000).

Enquanto governança, de forma ampla, trata da aquisição e distribuição de poder na sociedade, a governança corporativa diz respeito à maneira pela qual as corporações são governadas e gerenciadas. Geralmente a 
governança corporativa é tomada em contraste com a governança do setor público, a qual se refere à gestão dos órgãos e/ou entidades, embora os princípios de governança corporativa sejam também bastante aplicáveis no setor mais amplo do Estado, no qual as agências de serviços não públicos estão agrupadas (BHATTA, 2003).

Governança pública é entendida por Matias-Pereira (2010a, p. 113), "[...] como o sistema que determina o equilíbrio de poder entre todos os envolvidos numa organização - governantes, gestores, servidores, cidadãos com vista a permitir que o bem comum prevaleça sobre os interesses de pessoas ou grupos". A instituição, ao se desenvolver e atingir um melhor desempenho, alcança seus objetivos, que resultam em satisfação para todos os atores envolvidos.

Identificou-se, na literatura, que o Australian National Audit Office (Anao) divulgou, em 2003, o primeiro instrumento de governança no setor público e o Chartered Institute of Public Finance and Accountancy (CIPFA) o segundo, em 2004. Posteriormente outros instrumentos de governança foram surgindo, por exemplo, Clad (2006), IMF (2007), Brasil (2014), Ifac (2014), entre outros.

Em 2014, a Ifac, em conjunto com o CIPFA, publicaram o International Framework: Good Governance in the Public Sector (IFAC, 2014), que, em relação ao de 2004, amplia a área de cada princípio e acrescenta a dimensão de obtenção de resultados econômico, social e ambiental sustentáveis como um foco importante nos processos e estruturas de governança. Destaca também o foco de longo prazo para a responsabilidade dos gestores que vai além dos eleitores correntes, pois devem levar em conta o impacto de suas ações e decisões atuais sobre as futuras gerações.

Até recentemente, o Brasil carecia de um código de governança para o setor público. As discussões em torno desse assunto eram pautadas tanto no Código das Melhores Práticas de Governança Corporativa do IBGC, quanto nos códigos de órgãos multilaterais.

Não obstante, em 2014, o TCU publicou o Governança Pública: referencial básico de governança aplicável a órgãos e entidades da administração pública e ações indutoras de melhoria. Apresenta a seguinte definição para governança no setor público: "[...] um conjunto de mecanismos de liderança, estratégia e controle postos em prática para avaliar, direcionar e monitorar a gestão, com vistas à condução de políticas públicas e à prestação de serviços de interesse da sociedade" (BRASIL, 2014, p. 10, grifos do autor). O Brasil dispõe também de exigências normativas que tratam da transparência e do acesso à informação e, consequentemente, direta ou indiretamente, da governança.

Para o CIPFA (2004), a governança tem a função de garantir que uma organização cumpra totalmente os seus propósitos, alcance os resultados pretendidos para os stakeholders e opere de uma forma ética, eficaz e eficiente.

A versão atual da Ifac (2014) é resultado do estudo conjunto com o CIPFA e posiciona-se afirmando que a governança no setor público compreende a estrutura (administrativa, política, econômica, social, ambiental, legal e outras) posta em prática para assegurar que os resultados pretendidos para os stakeholders sejam definidos e alcançados.

Como se observa nas definições de governança para o setor público, a sociedade e/ou os stakeholders estão contemplados e, para que isso aconteça de maneira plena, os princípios de disclosure e transparência são de importância fundamental.

A boa governança pública, a exemplo da corporativa, está apoiada em quatro princípios básicos: fairness (equidade), disclosure e transparência, accountability e compliance (responsabilidade corporativa). MatiasPereira (2010b) salienta que a busca permanente da prática desses princípios na gestão do País ou de qualquer instituição deve ser vista como uma condição crucial para que essa instituição possa continuar a progredir. É uma tarefa permanente, que exige uma participação proativa de todos os atores envolvidos - dirigentes, políticos, órgãos de controle - e, em especial, da sociedade organizada. No entanto, como pondera a OCDE (2004), os princípios de governança são de natureza dinâmica e deverão ser revistos à luz de mudanças significativas em seus vetores.

\section{Relatórios de Gestão}

Entre as inúmeras variáveis que podem evidenciar as informações das UFs, este estudo estará circunscrito, basicamente, nos RGs das UFs referentes ao exercício de 2013, considerando que a LAl somente foi 
regulamentada pelo Decreto $\mathrm{n}^{\circ} 7.724 / 2012$ (BRASIL, 2012), portanto os relatórios, a partir do ano de 2013 , poderão conter maiores impactos da referida Lei. O estudo se restringe ao conteúdo do RG anual, por ser uma consolidação das informações financeiras e não financeiras da gestão pública, assim como um instrumento efetivo de accountability do gestor perante os órgãos de controle e a sociedade, pela utilização de fundos públicos (BRASIL, 1988, 1992, 2010).

Apesar de existirem as Demonstrações Contábeis (DCs), estabelecidas pelas Normas Brasileiras de Contabilidade (NBCs), editadas pelo Conselho Federal de Contabilidade (CFC), a serem elaboradas e divulgadas pelas entidades do setor público, que também compõem as peças para a prestação de contas dos gestores públicos, o RG possui uma configuração que facilita sua leitura por parte daqueles que não possuem uma formação na área contábil. Em outras palavras, as DCs apresentam uma terminologia técnica que boa parte dos cidadãos não compreende, ao passo que os RGs têm uma linguagem um pouco mais acessível. Entretanto, esses últimos são extensos, apresentados de forma complexa e também de difícil assimilação para os usuários que não são da área contábil e/ou financeira.

Além disso, a apresentação tempestiva do RG configura o cumprimento da obrigação de prestar contas, nos termos do parágrafo único do art. 70 da CF/1988 (BRASIL, 1988). Alcança toda a APF (direta e indireta) e deve conter elementos e demonstrativos que evidenciem a regular aplicação dos recursos públicos, o controle da sua conformidade e o desempenho da gestão com o propósito de contribuir para o aperfeiçoamento da gestão pública (BRASIL, 2010).

A prestação de contas prevista na Constituição Brasileira confere a dimensão de sua relevância, representando um dos principais instrumentos de accountability do uso de recursos públicos perante a sociedade. Para seu funcionamento, os entes públicos são financiados pela sociedade, por meio de pagamento de tributos, o que torna os cidadãos os principais beneficiários dos resultados a serem gerados pela atuação do Estado. Nessa perspectiva, deve ser processo natural dos gestores públicos prestar contas de sua gestão aos vários atores nela interessados (stakeholders).

A elaboração do RG deve permitir uma visão sistêmica do desempenho e da conformidade da gestão dos seus responsáveis de acordo com o previsto no inciso II do art. $1^{\circ}$ da IN TCU n 63/2010 (BRASIL, 2010). Ademais, deve ser pautada pelas características da informação contábil no setor público, conforme estipulado nas Resoluções CFC $n^{\circ}$ 1.132/2008 e $n^{\circ}$ 1.366/2011 (CFC, 2012): comparabilidade, compreensibilidade, confiabilidade, fidedignidade, imparcialidade, integridade, objetividade, representatividade, tempestividade, uniformidade, utilidade, verificabilidade, visibilidade, especificidade e granularidade.

\section{Metodologia}

Para analisar o nível de transparência nos RGs das UFs, calcou-se na literatura e nos princípios e padrões de boas práticas de governança estabelecidos para a APF, elaborados por instituições internacionais e brasileiras. Os princípios e padrões dos instrumentos pesquisados cobrem o período de 2004 a 2014. Para identificação desses instrumentos, foi pesquisado o sítio eletrônico da European Corporate Governance Institute (ECGI), além de diversos sítios de organizações multilaterais e, no caso brasileiro, o sítio do TCU. Trata-se de uma pesquisa de natureza exploratória, descritiva e qualitativa com base na técnica da análise de conteúdo (BARDIN, 2004).

Para se determinar o nível de transparência dos RGs das UFs, foi utilizada uma escala de intensidade (BARRAZA-MACÍAS, 2008; MALDONADO-RADILLO, 2013) na qual é apresentada a relação de probabilidade de ocorrência dos eventos, com cinco graus de escala de valores. Essa escala foi construída em função dos percentuais de pontuação máxima a serem atingidos pelas UFs, os quais variarão entre 0 e $100 \%$ e classificam os níveis de transparência em: baixo (0 a 20\%), médio-baixo (21 a 40\%), médio (41 a 60\%), médio-alto (61 a $80 \%$ ) e alto (81 a 100\%).

O universo da pesquisa são as 63 universidades públicas federais: 38 autarquias e 25 fundações, conforme especificadas na Decisão Normativa (DN) TCU n 134/2013 (BRASIL, 2013). Foram selecionadas cinco universidades, uma de cada região geográfica do Brasil (Norte, Nordeste, Centro-Oeste, Sudeste e Sul). Para a seleção da amostra, optou-se por utilizar o ranking da Webometrics Ranking of World Universities. No World Ranking, de julho de 2013 (WEBOMETRICS, 2013), foram classificadas 16 universidades brasileiras. Dentre elas, selecionou-se a que mais se destacou no ranking, de acordo com suas respectivas regiões do Brasil. Desse modo, foram escolhidas as seguintes instituições, por região: 
- $\quad$ Norte: Universidade Federal do Pará (UFPA);

- Nordeste: Universidade Federal da Bahia (UFBA);

- Centro-Oeste: Universidade de Brasília (UnB);

- $\quad$ Sudeste: Universidade Federal de Minas Gerais (UFMG);

- Sul: Universidade Federal do Rio Grande do Sul (UFRGS).

O objeto de estudo foram os RGs do exercício de 2013 das cinco universidades selecionadas. A transparência foi analisada a partir dos RGs dessas cinco UFs, disponíveis nos seus próprios websites.

\section{Análise dos dados}

O tratamento e análise dos dados foram efetuados, por meio de tabelas, com suas categorias de análise, contendo as métricas das melhores práticas de governança, distribuídas em subcategorias relacionadas com a transparência, tendo como base os princípios e padrões de boas práticas de governança da APF e/ou identificação dessas práticas na literatura consultada. Os dados dos RGs de cada uma das universidades selecionadas foram confrontados com as métricas das subcategorias de análise para se avaliar a aderência dos RGs das universidades às subcategorias das melhores práticas de boa governança do setor público, associadas à transparência.

Para a elaboração das categorias de análise e suas respectivas subcategorias, adotou-se, como ponto de partida, o modelo metodológico já utilizado por Bizerra (2011), efetuando-se as devidas adaptações para Relatório de Gestão e para universidades. Também foram feitas adequações e estabelecidas outras categorias e subcategorias, tendo em vista novas referências nacionais e estrangeiras, legislações, notadamente a LAl e sua regulamentação, novos códigos de boa governança no setor público e/ou suas atualizações e a legislação específica do TCU acerca do RG, de modo a abranger uma variedade considerável de aspectos essenciais que caracterizem a boa governança para a obtenção da transparência. Dessa forma foram identificadas 13 categorias e 110 subcategorias.

Pontuou-se cada subcategoria, utilizando-se uma pontuação dicotômica $[1$ = atendido pelo RG analisado, e 0 = quando não atendido] em relação à análise dos relatórios de cada uma das universidades.

Contudo, neste estudo, por representar um recorte da pesquisa de doutorado, será apresentada apenas a categoria disclosure e suas 18 subcategorias, as quais foram dispostas na Tabela 1. Se essas subcategorias fossem todas atendidas, considerar-se-iam 100\% de aderência à transparência nos RGs das UFs, para a categoria aqui focalizada.

Tabela 1 - Subcategorias de Disclosure

\begin{tabular}{l|l|c|c|c|c|c|c}
\hline \multicolumn{1}{|c|}{ Item } & \multicolumn{1}{|c|}{$\begin{array}{c}\text { Pontos } \\
\text { máximos }\end{array}$} & UFBA & UFMG & UFPA & UFRGS & UnB \\
\hline & Disponibilização das DCs ao público: & & & & & & \\
\hline 1 & a) Balanço Patrimonial & 1 & 1 & 1 & 0 & 1 & 0 \\
\hline 2 & b) Balanço Orçamentário & 1 & 0 & 1 & 0 & 1 & 0 \\
\hline 3 & c) Balanço Financeiro & 1 & 1 & 1 & 0 & 1 & 0 \\
\hline 4 & d) Demontração das Variações Patrimoniais & 1 & 0 & 1 & 0 & 1 & 0 \\
\hline
\end{tabular}

Fonte: Adaptado de Bizerra (2011, p. 85-86).

Legenda: UFBA - Universidade Federal da Bahia; UFMG - Universidade Federal de Minas Gerais; UFPA Universidade Federal do Pará; UFRGS - Universidade Federal do Rio Grande do Sul; UnB - Universidade de Brasília 
Tabela 1 - Subcategorias de Disclosure (Continuação)

\begin{tabular}{|c|c|c|c|c|c|c|c|}
\hline Item & Descrição & $\begin{array}{l}\text { Pontos } \\
\text { máximos }\end{array}$ & UFBA & UFMG & UFPA & UFRGS & UnB \\
\hline 5 & e) Demonstração dos Fluxos de Caixa & 1 & 0 & 0 & 0 & 0 & 0 \\
\hline 6 & $\begin{array}{l}\text { f) Demonstração das Mutações do Patrimônio Líquido } \\
\text { (DMPL) }\end{array}$ & 1 & 0 & 1 & 0 & 0 & 0 \\
\hline 7 & g) Notas Explicativas & 1 & 0 & 0 & 0 & 1 & 0 \\
\hline 8 & $\begin{array}{l}\text { Divulgação das DCs de forma comparativa - último } \\
\text { exercício e exercício anterior }\end{array}$ & 1 & 1 & 1 & 0 & 1 & 0 \\
\hline 9 & $\begin{array}{l}\text { Descrição sintética nos RGs dos planos estratégico, } \\
\text { tático e operacional que orientam a universidade }\end{array}$ & 1 & 0 & 1 & 1 & 1 & 1 \\
\hline 10 & $\begin{array}{l}\text { Disponibilização de relatório de prestação de contas } \\
\text { para os stakeholders de modo a facilitar a análise das } \\
\text { políticas e promover a accountability }\end{array}$ & 1 & 0 & 1 & 0 & 1 & 0 \\
\hline 11 & $\begin{array}{l}\text { Publicação de informações sobre a investigação da } \\
\text { visão dos usuários dos serviços acerca da adequação } \\
\text { e qualidade dos serviços que recebem }\end{array}$ & 1 & 0 & 1 & 0 & 0 & 0 \\
\hline 12 & Divulgação de planos e projetos futuros & 1 & 1 & 1 & 1 & 1 & 1 \\
\hline 13 & $\begin{array}{l}\text { Divulgação das responsabilidades sobre plane-jamento } \\
\text { e execução orçamentária, eficácia da estrutura de } \\
\text { controle e gestão de riscos, ade-quação das DCs, } \\
\text { responsabilidade pelo uso de normas contábeis } \\
\text { adequadas, responsabilidade da alta administração } \\
\text { acerca das DCs }\end{array}$ & 1 & 0 & 0 & 0 & 0 & 0 \\
\hline 14 & $\begin{array}{l}\text { Relação dos principais parceiros (externos à uni- } \\
\text { versidade, da área pública ou da iniciativa privada) } \\
\text { relacionados com a atividade-fim }\end{array}$ & 1 & 0 & 1 & 1 & 1 & 1 \\
\hline 15 & $\begin{array}{l}\text { Disponibilização dos RGs, desde } 2004 \text {, no Portal da } \\
\text { Universidade }\end{array}$ & 1 & 1 & 0 & 1 & 1 & 1 \\
\hline 16 & $\begin{array}{l}\text { Usabilidade no sítio eletrônico da universidade, em } \\
\text { apenas um único click, chega ao RG }\end{array}$ & 1 & 0 & 1 & 0 & 0 & 0 \\
\hline 17 & $\begin{array}{l}\text { RGs disponibilizados nos Portais das Universidades } \\
\text { em formatos de dados abertos, de forma a facilitar o } \\
\text { seu uso, reúso e redistribuição }\end{array}$ & 1 & 0 & 0 & 0 & 0 & 0 \\
\hline \multirow[t]{3}{*}{18} & $\begin{array}{l}\text { Publicação do RG na Web (exercício de 2013, data- } \\
\text { limite de envio ao TCU: } 31-3-2014 \text {. Admite-se que, até } \\
\text { essa data, também deveria ser disponibilizado no sítio } \\
\text { eletrônico da universidade para livre acesso dos } \\
\text { stakeholders) }\end{array}$ & 1 & 0 & 0 & 0 & 0 & 1 \\
\hline & Total de pontos & 18 & 5 & 12 & 4 & 11 & 5 \\
\hline & Percentual máximo de pontos (\%) & 100,00 & 27,78 & 66,67 & 22,22 & 61,11 & 27,78 \\
\hline
\end{tabular}


A categoria disclosure evidencia a disponibilização dos dados e informações da universidade aos stakeholders, admitindo-se o sigilo como exceção, nos termos da lei. É uma das mais importantes categorias, pois é por meio do disclosure que é possível auferir a maioria das demais categorias.

Na categoria disclosure, a UFMG, pertencente à Região Sudeste, foi a que apresentou melhor desempenho (66,67\%), seguida da UFRGS (61,11\%), da Região Sul. A UFBA da Região Nordeste e a UnB da Região CentroOeste ficaram na terceira posição $(27,78 \%)$ e a UFPA, da Região Norte, apresentou o resultado mais baixo $(22,22 \%)$. Uma das explicações para a baixa pontuação pode ser a não divulgação das DCs por parte de algumas universidades, por considerarem-se desobrigadas de tal publicação porque executam suas contabilidades pelo Sistema Integrado de Administração Financeira do Governo Federal (Siafi). Adicionalmente, algumas optaram por evidenciar informação de natureza financeira, não obrigatória para esse tipo de segmento, como exemplo, a DMPL, que não é obrigatória para as UFs, mas foi divulgada de forma expontânea pela UFMG. A publicização das DCs, principalmente no sítio eletrônico das respectivas instituições, é um instrumento a mais a colaborar com o disclosure e, consequentemente, com a transparência e a accountability. Em outras palavras, é uma das maneiras de prestar contas à sociedade, legitimando as ações e zelando pela transparência. Esses percentuais poderão ser visualizados melhor no Gráfico 1.

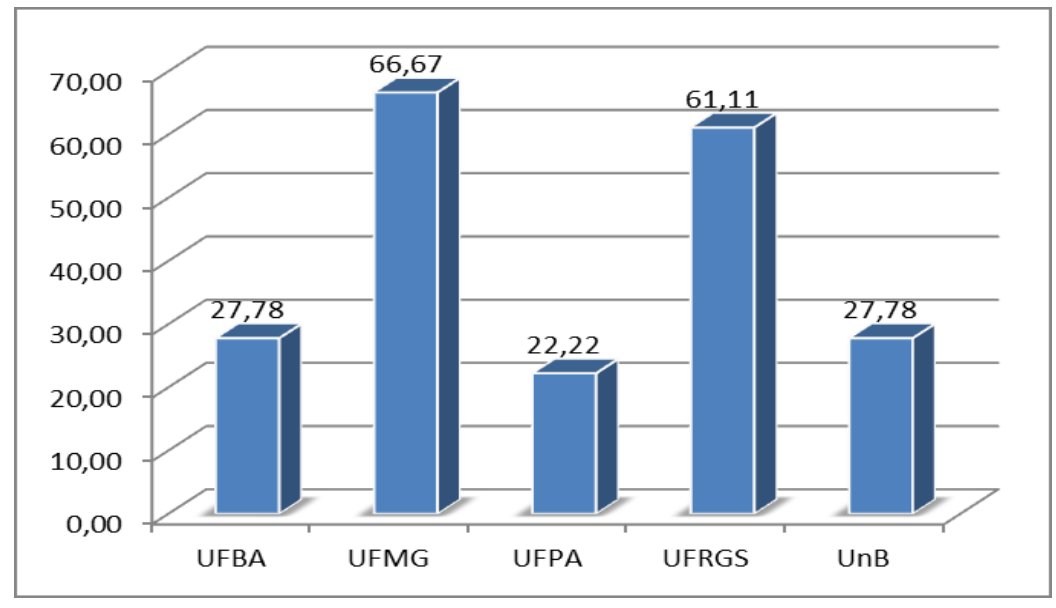

Gráfico 1 - Percentual máximo e de cada universidade em relação à categoria disclosure.

Fonte: Elaboração própria, com base nos dados da pesquisa.

Legenda: UFBA - Universidade Federal da Bahia; UFMG - Universidade Federal de Minas Gerais; UFPA -

Universidade Federal do Pará; UFRGS - Universidade Federal do Rio Grande do Sul; UnB - Universidade de Brasília

Destaca-se que, com a Lei Complementar no 101/2000 (BRASIL, 2000), denominada Lei de Responsabilidade Fiscal (LRF) e a LAl, é dever dos órgãos e entidades promover, independente de solicitação, a divulgação em seus sítios na Internet de informações de interesse dos cidadãos, colaborando dessa forma com a transparência ativa. E o disclosure das DCs proporciona um melhor embasamento para a tomada de decisão, por comunicar aos seus usuários informações relevantes.

Ademais, muitos dados poderão ser publicados com base no disclosure voluntário (VERRECCHIA, 2001), chegando-se, assim, ao full disclosure e atingindo altos índices de transparência.

Como se pode observar tanto no Gráfico 1 quanto na Tabela 1, nenhuma das universidades analisadas atingiu o patamar da alta transparência de acordo com o que foi especificado na metodologia, acerca da intensidade do nível de transparência para a categoria disclosure. Os maiores percentuais foram auferidos pela UFMG seguida da UFRGS, classificando-as no nível de transparência médio-alto. Em seguida, classificaram-se a UFBA e a UnB $(27,78 \%)$ e por último a UFPA $(22,22 \%)$, todas com o nível de transparência médio-baixo. Os resultados parciais apurados evidenciam o fato de que ainda é reduzido o número de subcategorias do disclosure que foram atendidas pelos RGs das universidades, para classificá-las em patamares mais significativos. 


\section{Conclusões}

O presente estudo teve como objetivo principal analisar em que medida os Relatórios de Gestão das Universidades Federais atendem aos princípios de boa governança estabelecidos para a APF segundo diretrizes nacionais e internacionais. Para tanto, apoiou-se na teoria do agente-principal, uma vez que o relacionamento de seus atores - Estado e cidadãos - quando não alinhado, tende a ser conflitante e pode gerar problemas na condução da boa governança dos contratos.

Os resultados observados na categoria disclosure com 18 subcategorias das 110 identificadas demonstram que: nenhuma das universidades analisadas atingiu o patamar da alta transparência; os maiores percentuais foram auferidos pela UFMG e UFRGS, classificando-as no nível de transparência médio-alto. Em seguida, a UFBA e a UnB e por último a UFPA, todas no nível de transparência médio-baixo.

Ressaltam-se as limitações de que os resultados não podem ser generalizados, uma vez que se referem a uma única universidade de cada região do Brasil. Foram apresentadas apenas 18 subcategorias das 110 especificadas e, na abordagem qualitativa, por meio da técnica de análise de conteúdo, o pesquisador desempenha papel crucial na análise dos dados e informações, constituindo-se, dessa forma, de um pouco de subjetividade que poderá influenciar a aferição das métricas utilizadas.

Finalmente, apesar de o estudo estar focado nas universidades, espera-se que contribua com aportes teóricos no sentido de complementar e enriquecer a bibliografia acerca do tema e em termos práticos na perspectiva de auxiliar os gestores, sociedade e stakeholders interessados na transparência das informações das UFs. Também poderá contribuir para que os princípios de boa governança se tornem amplamente aplicados na APF para obtenção da transparência da informação, aspecto fundamental às sociedades democráticas, e assim colaborar na promoção do controle social, na ampliação da cidadania, no combate à corrupção, na melhoria da gestão pública, entre outros.

\section{Referências}

ALCHIAN, A. A.; DEMSETZ, H. Production, information costs and economic organization. The American Economic Review, v. 62 , n. 5, p. 777-795, 1972.

BAIRRAL, M. A. da C.; SILVA, A. Transparência no setor público: uma análise do nível de transparência dos relatórios de gestão dos entes públicos federais no exercício de 2010. In: ENCONTRO DA ASSOCIAÇÃO NACIONAL DE PÓSGRADUAÇÃO E PESQUISA EM ADMINISTRAÇÃO (EnANPAD), 37., 2013, Rio de Janeiro. Anais eletrônicos... Rio de Janeiro: Anpad, 2013. Disponível em: <http://www.anpad.org.br/ diversos/trabalhos/EnANPAD/enanpad 2013/03\%20\%20CON/PDF\%20CON\%20-\%20Tema\%204/2013_EnANPAD_CON 1819.pdf>. Acesso em: 3 jun. 2014.

BARDIN, L. Análise de conteúdo. 3. ed. Lisboa: Edições 70, 2004.

BARRAZA-MACÍAS, A. Compromiso organizacional de los docentes: um studio exploratorio. Revista de la Associación de Inspectores en Educación en España, n. 8, 2008.

BHATTA, G. Post-NPM themes in public sector governance. State Services Commission. Working paper $n$. 17, p. 1-15, Sept. 2003. Disponível em: <http://www.ssc.govt.nz/upload/downloadable files/Post-NPM Themes In Public Sector_Governance.pdf>. Acesso em: 27 jul. 2014.

BIZERRA, A. L. V. Governança no setor público: aderência dos relatórios de gestão do Poder Executivo municipal aos princípios e padrões de boas práticas de governança. 2011. 124 f. Dissertação (Mestrado em Ciências Contábeis) Universidade do Estado do Rio de Janeiro, Rio de Janeiro, 2011

BRASIL. Tribunal de Contas da União. Resolução TCU $n^{\circ}$ 206, de 27 de novembro de 1980. Dispõe sobre o exercício da auditoria financeira e orçamentária, o julgamento das contas dos responsáveis por bens e valores públicos e dá outras providências. 1980. Disponível em: <https://contas.tcu.gov.br/juris/Web/Juris/ ConsultarAto

Normativo/ConsultarAtoNormativo.faces>. Acesso em: 13 jun. 2014.

BRASIL. Constituição (1988). Constituição [da] República Federativa do Brasil. 1988. Disponível em: <http://www.planalto.gov.br/ccivil 03/Constituicao/ Constituicao.htm>. Acesso em: 30 set. 2013.

BRASIL. Lei $n^{\circ}$ 8.443, de 16 de julho de 1992. Dispõe sobre a Lei Orgânica do Tribunal de Contas da União e dá outras providências. 1992. Disponível em: <http://www. planalto.gov.br/ ccivil 03/Leis/L8443.htm>. Acesso em: 21 jun. 2014.

BRASIL. Tribunal de Contas da União. Instrução Normativa TCU $n^{\circ}$ 6, de 8 de junho de 1994. Estabelece normas de organização e apresentação de tomadas e prestações de contas e rol de responsáveis, e dá outras providências. 1994. Disponível em: <https://contas.tcu.gov.br/juris/Web/Juris/ConsultarAtoNormativo/ ConsultarAtoNormativo.faces>. Acesso em: 13 jun. 2014 
BRASIL. Lei Complementar $n^{\circ} 101$, de 4 de maio de 2000. Estabelece normas de finanças públicas voltadas para a responsabilidade na gestão fiscal e dá outras providências. 2000. Disponível em: <http://www. planalto.gov.br/ccivil 03/Leis/LCP/ Lcp101. htm>. Acesso em: 23 maio 2013.

BRASIL. Tribunal de Contas da União. Instrução Normativa TCU $n^{\circ} 63$, de $1^{\circ}$ de setembro de 2010. Estabelece normas de organização e apresentação dos relatórios de gestão e das peças complementares que constituirão os processos de contas da administração pública federal, para julgamento do Tribunal de Contas da União, nos termos do art. $7^{\circ}$ da Lei $n^{\circ} 8.443$, de 1992. 2010. Disponível em: <https://contas.tcu.gov.br/juris/Web/Juris/ConsultarAtoNormativo/ConsultarAto Normativo.faces> Acesso em: 24 mar. 2014

BRASIL. Decreto $n^{\circ}$ 7.724, de 16 de maio de 2012. Regulamenta a Lei $n$ ำ 12.527 , de 18 de novembro de 2011 , que dispõe sobre o acesso a informações previsto no inciso XXXIII do caput do art. $5^{\circ}$, no inciso II do $\S 3^{\circ}$ do art. 37 e no $\S 2^{\circ}$ do art. 216 da Constituição. 2012. Disponível em: <http://www.planalto.gov.br/CCIVIL 03/ Ato2011-2014/2012/Decreto/ D7724.htm>. Acesso em: 30 set. 2013

BRASIL. Tribunal de Contas da União. Decisão Normativa TCU $n^{\circ} 134$, de 4 de dezembro de 2013. Dispõe acerca das unidades jurisdicionadas cujos dirigentes máximos devem apresentar relatório de gestão referente ao exercício de 2014 especificando a organização, a forma, os conteúdos e os prazos de apresentação, nos termos do art. $3^{\circ}$ da IN TCU $n^{\circ} 63$, de $1^{\circ}$ de setembro de 2010. 2013. Disponível em

<https://contas.tcu.gov.br/juris/Web/Juris/ConsultarTextual2/Normativos.faces>. Acesso em: 3 jun. 2014.

BRASIL. Tribunal de Contas da União. Governança Pública: referencial básico de governança aplicável a órgãos e entidades da administração pública e ações indutoras de melhoria. Brasília: TCU, Secretaria de Planejamento, Governança e Gestão. 2014. Disponível em: <http://portal2.tcu.gov.br/portal/pls/portal/ docs/2642557.PDF>. Acesso em: 21 jul. 2014.

CANELA, G.; NASCIMENTO, S. (Coord.). Acesso à informação e controle social das políticas públicas. Brasília, DF: Andi; Artigo 19, 2009

CENTRO LATINOAMERICANO DE ADMINISTRACIÓN PARA EL DESAROLLO (CLAD). Código iberoamericano de buen gobierno. Jun. 2006. Disponível em: <http://old.clad.org/documentos/declaraciones/codigoiber.pdf/view>. Acesso em: 13 out. 2013.

CENTRO LATINOAMERICANO DE ADMINISTRACIÓN PARA EL DESAROLLO (CLAD). Carta iberoamericana de gobierno electrónico. Jun. 2007. Disponível em: <http://siare.clad.org/siare/innotend/gobelec/gobelec.html>. Acesso em: 14 nov. 2014

CHARTERED INSTITUTE OF PUBLIC FINANCE AND ACCOUNTANCY (CIPFA). Good governance standard for public services. 2004. Disponivel em: <http://www.jrf.org.uk/system/files/1898531862.pdf>. Acesso em: 17 maio 2014.

COASE, R. H. The nature of the firm. Economica, London, v.4, n. 16, p. 386-405, 1937

CONSELHO FEDERAL DE CONTABILIDADE (CFC). Normas brasileiras de contabilidade: contabilidade aplicada ao setor público: NBCs T 16.1 a 16.11/ Conselho Federal de Contabilidade. Brasília: Conselho Federal de Contabilidade, 2012.

FOX, J. A. The uncertain relationship between transparency and accountability. Development in Practice, v. 17, n. 4-5, p. 662671, Aug. 2007. Disponível em: < http://escholarship.org/uc/item/8c25c3z4>. Acesso em: 14 out. 2013.

GALLEGO, I.; GARCÍA, I.; RODRÍGUEZ, L. Universities' websites: disclosure practices and the revelation of financial information. The International Journal of Digital Accounting Research, Huelva, Spain, v. 9, p. 153-192, 2009. Disponível em: <http://www.uhu.es/ijdar/10.4192/1577-8517-v9 6.pdf>. Acesso em: 10 jun. 2014.

GORDON, T. et al. A comparative empirical examination of extent of disclosure by private and public colleges and universities in the United States. Journal of Accounting and Public Policy, v. 21, n. 3 p. 235-275, Autumn, 2002.

GRAY, R.; HASLAM, J. External reporting by UK universities: an exploratory study of accounting change. Financial Accountability and Management, v. 6, n. 1, p. 51-72, Mar. 1990

GÜEMES, M. C.: RAMÍREZ-ALUJAS, A. V. Gobierno abierto, reforma del Estado y modernización de la gestión pública: alcances, obstáculos y perspectivas en clave Latinoamericana. In: HOFMANN, A.; RAMÍREZ-ALUJAS, A.; PEREZNIETO, J. A B. (Coord.). La promesa del gobierno abierto. 2012. cap. 3, p. 193-224.Disponível em: <http://www.lapromesadelgobiernoabierto.info/lpga.pdf>. Acesso em: 16 nov. 2014.

INTERNATIONAL FEDERATION OF ACCOUNTANTS (Ifac). Governance in the public sector: a governing body perspective: international public sector study (Study 13). New York, Aug. 2001. Disponível em: <http://www.ifac. org/ sites/default/ files/ publications/files/study-13-governance-in-th.pdf>. Acesso em: 7 out. 2013

INTERNATIONAL FEDERATION OF ACCOUNTANTS (Ifac). International Framework: Good Governance in the Public Sector July 2014. Disponível em: < https://www.ifac.org/publications-resources/international-framework-good-governance-publicsector>. Acesso em: 18 jul. 2014

INTERNATIONAL MONETARY FUND (IMF). Code of good practices on fiscal transparency (2007). Disponível em: <http://www.imf.org/external/np/pp/2007/eng/ 051507c.pdf>. Acesso em: 17 maio 2014 
JARDIM, J. M. Transparência e opacidade do Estado no Brasil: usos e desusos da informação governamental. Niterói: EdUFF, 1999.

JENSEN, M.C.; MECKLING, W. H. Theory of the firm: managerial behavior, agency costs and ownership structure. Journal of Financial Economics, v. 3, n. 4, p. 305-360, 1976.

KLEIN, B. Contracting costs and residual claims: the separation of ownership and control. Journal of Law and Economics, v. 26, n.2, p. 367-374, 1983.

LIMA, E. M. Análise comparativa entre o índice disclosure e a importância atribuída por stakeholders a informações consideradas relevantes para fins de divulgação em instituições de ensino superior filantrópicas do Brasil: uma abordagem da teoria da divulgação, 2009, 201 f. Tese (Doutorado em Ciências Contábeis) - Universidade de São Paulo, São Paulo, 2009.

LÓPEZ, R. P. Gobierno abierto en Latinoamérica: análisis de los procesos y las iniciativas. In: CONGRESO INTERNACIONAL DEL CLAD SOBRE LA REFORMA DEL ESTADO Y DE LA ADMINISTRACIÓN PÚBLICA, 18., 2013, Montevideo, Uruguay Anais... Venezuela: CLAD, 2013.

MACHADO, J. Dados abertos e ciência aberta. In: ALBAGLI, S.; MACIEL, M. L.; ABDO, A. H. (Org.). Ciência aberta, questões abertas. Brasília: IBICT; Rio de Janeiro: UNIRIO, 2015. cap. 9, p. 201-227.

MALDONADO-RADILLO, S. E. et al. La transparencia de la instituciones públicas de educación superior del nordeste de México. Revista Internacional Administracion \& Finanzas, v. 6. n. 4. p. 73-88, 2013. Disponível em: < http://www.theibfr. com/ARCHIVE/RIAF-V6N4-2013.pdf>. Acesso em: 6 set. 2014.

MARQUES, M. da C. da C. Aplicação dos princípios da governança corporativa ao setor público. Revista de Administração Contemporânea, Curitiba, v. 11, n. 2, p. 11-26, abr./jun. 2007.

MATIAS-PEREIRA, J. Governança no setor público. São Paulo: Atlas, 2010a.

MATIAS-PEREIRA, J. Curso de Administração Pública: foco nas instituições e ações governamentais. 3. ed. São Paulo: Atlas 2010b.

MATTELART, A. História da sociedade da informação. Tradução de Nicolás Nyimi Campanário. São Paulo: Edições Loyola, 2002

MICHENER, G.; BERSCH, K. Conceptualizing the quality of transparency. In: $1^{\text {ST }}$ GLOBAL CONFERENCE ON TRANSPARENCY, Rutgers University, Newark, May 17-20, 2011. Anais eletrônicos... Disponível em: $<$ http://gregmichener.com/ Conceptualizing the Quality ofTransparency--Michener and Bersch for Global Conference on Transparency.pdf>. Acesso em: 26 maio 2013.

NELSON, M.; BANKS, W.; FISHER, J. Improved accountability disclosures by Canadian Universities. Canadian Accounting Perspectives, v. 2, n. 1, p. 77-107, May 2003.

NETHERLANDS. Ministry of Finance. Government Audit Policy Directorate. Government governance: corporate governance in the public sector, why and how?. Hague, Nov. 2000. This paper was first presented on 2 Nov. 2000 on the occasion of the 9th fee Public Sector Conference (Nov. 2000). Disponível em: <http://www.ecgi. org/codes/documents/public sector.pdf>. Acesso em: 20 mar. 2014.

NOGUEIRA, M. A. As possibilidades da política: ideias para a reforma democrática do Estado. São Paulo: Paz e Terra, 1998.

OBAMA, B. Memorandum on Transparency and Open Government (OGD), Executive Office of the President of United States of America, Washington, DC, 8 Dec 2009. Disponível em: <http://www. whitehouse.gov/sites/default/files/omb/assets/ memoranda 2010/m10-06.pdf>. Acesso em: 17 nov. 2014.

OPEN KNOWLEDGE FOUNDATION. Open Data Handbook Documentation. Release 1.0.0. Cambridge, UK. Nov. 2012. Disponível em: <https://okfn.org/opendata/>. Acesso em: 12 nov. 2014.

ORGANISATION FOR ECONOMIC CO-OPERATION AND DEVELOPMENT (OECD). OECD Principles of Corporate Governance. França: OECD Publication, 2004. Disponível em: <http://www.oecd.org/daf/ca/corporategovernanceprinciples/ 31557724.pdf>. Acesso em: 4 out. 2013.

ORGANISATION FOR ECONOMIC CO-OPERATION AND DEVELOPMENT (OECD). Building an open and innovative government for better policies and service delivery. Session 1: OECD Guiding principles for open and inclusive policy making. 2010. Disponível em: < http://www.oecd.org/gov/46560128.pdf >. Acesso em: 13 nov. 2014.

OSZLAK, Oscar; KAUFMAN, Ester. Teoría y práctica de gobierno aberto: lecciones de la experiencia internacional. IDRCCRDI/REDGEALC/OEA, ago/2014. Disponível em: < http://www.redgealc.org/gobierno-abierto/tema/26/es/>. Acesso em: 2 nov. 2014.

PESSÔA, I. da S. Determinantes da transparência das universidades federais brasileiras. 2013. 175 f. Dissertação (Mestrado em Gestão Pública) - Universidade Federal do Espírito Santo, Vitória, 2013. 
PLATT NETO, O. A.; CRUZ, F. da; VIEIRA, A. L. Transparência das contas públicas das universidades: um enfoque no uso da Internet como instrumento de publicidade. In: COLÓQUIO INTERNACIONAL SOBRE GESTÃO UNIVERSITÁRIA NA AMÉRICA DO SUL, 4., 2004, Florianópolis. Anais eletrônicos... Florianópolis: UFSC, 2004. Disponível em: <http://www.inpeau.ufsc.br/coloquio04/a9.htm>. Acesso em: 29 jul. 2014.

POLIZEL, C.; STEINBERG, H. Governança corporativa na educação superior: casos práticos de instituições privadas (com e sem fins lucrativos). São Paulo: Saraiva, 2013.

RODRIGUES, G. M. Indicadores de "transparência ativa" em instituições públicas: analise dos portais de universidades públicas federais. Liinc em Revista, Rio de Janeiro, v. 9, n. 2, p. 423-438, nov. 2013.

RosS, S. A. The economic theory of agency: the principal's problem. The American Economic Review, v. 63, n. 2, p. 134-139, May 1973.

ROSSETTI, J. P.; ANDRADE, A. Governança corporativa: fundamentos, desenvolvimentos e tendências. 6. ed. São Paulo: Atlas, 2012.

SCHNACKENBERG, A. Measuring transparency: towards a greater understanding of systemic transparence and accountability. Working paper 09-02, Weatherhead School of Management. Cleveland, Ohio. 2009. Disponível em: <https:// weatherhead.case. edu/ departments/organizational-behavior/workingPapers/WP-09-02.pdf.> Acesso em: 7 out. 2013.

SCHNACKENBERG, A. K.; TOMLINSON, E. C. Organizational transparency: a new perspective on managing trust in organization-stakeholder relationships. Journal of Management, v. XX, n. X, p. 1-27, 2014

SCHOLTES, E. Transparency, symbol of a drifting government. In: TRANSATLANTIC CONFERENCE ON TRANSPARENCY RESEARCH, 2012, Utrecht, The Netherlands. Disponível em: <http://www.transparencyconference.nl/ wp-content/uploads/2012/05/Scholtes1.pdf>. Acesso em: 22 abr. 2013.

SILVA, C. E. T.; VASCONCELOS, A. L. F. de S.; SILVA, M. N. da. Prestação de contas: a evidenciação dos conteúdos informativos no relatório de gestão da UFPE. In: COLÓQUIO INTERNACIONAL SOBRE GESTÃO UNIVERSITÁRIA NAS AMÉRICAS, 12., 2013, Buenos Aires. Anais eletrônicos... Disponível em:

<https://repositorio.ufsc.br/handle/123456789/114865>. Acesso em: 11 mar. 2015.

SLOMSKI, V. et al. Governança corporativa e governança na gestão pública. São Paulo: Atlas, 2008.

STIGLITZ, J. Transparency in Government. In: WORLD BANK INSTITUTE. The right to tell: the role of mass media in economic development. Washington, D.C: The World Bank, 2002. p. 27-44.

TRANSPARENCY INTERNATIONAL. Guía de lenguaje claro sobre la lucha contra la corrupción. 2009. Disponível em: <http://www. transparencia.pt/wp-content/uploads/ 2012/03/Plain-Language-Guide-ES.pdf>. Acesso em: 8 nov. 2014.

VERRECCHIA, R. E. Essays on disclosure. Journal of Accounting and Economics, v. 32, p. 97-180, Dec. 2001.

WEBOMETRICS RANKING OF WORLD UNIVERSITIES (WEBOMETRICS). Ranking web of universities. 2013. Disponível em: <http://webometrics.info/en/Latin America/ Brazil>. Acesso em: 17 out. 2013.

YU, H.; ROBINSON, D. G. The new ambiguity of open government. UCLA Law Review Discourse, Los Angeles, v. 59, p. 178208, 2012. Disponível em: <http://ssrn.com/abstract=2012489>. Acesso em: 23 mar. 2015. 


\section{Dados dos autores}

\section{Luzia Zorzal}

Doutoranda em Ciência da Informação pela Universidade de Brasília (UnB) com bolsa Capes. Mestre em Ciências Contábeis pela Fundação Getúlio Vargas - FGV-RJ (1993). Pós-graduação lato sensu em Administração Universitária pela Universidade Federal do Espírito Santo - UFES (1987), Graduação em Ciências Contábeis pela Universidade Vila Velha - UVV (1982) e Graduação em Ciências Econômicas pela UFES (1979). Professora Adjunto IV da UFES onde leciona no Curso de graduação em Ciências Contábeis. Atua como avaliadora ad hoc do Sistema Nacional de Avaliação da Educação Superior (SINAES) do INEP/MEC, desde 2000. Atualmente se dedicando à área da Ciência da Informação com ênfase em disclosure, transparência, accountability, políticas, legislação e outros dispositivos normativos de controle da informação. luzia.zorzal@gmail.com

\section{Georgete Medleg Rodrigues}

Pós-doutorado na Université de Paris X (Département de sciences juridiques, administratives et politiques/Bibliothèque de Documentation Internationale Contemporaine-BDIC, Nanterre, França, 2008-2009). DEA (Diplôme d'études approfondies, 1992) e Doutorado (1998) em História, ambos pela Université de Paris (Paris IV-Sorbonne). Professora convidada da École Nationale des Chartes, Paris (fevereiro de 2011). Mestre em História pela Universidade de Brasília (1990). Graduada (bacharelado) em História pela Pontifícia Universidade Católica de São Paulo (PUC/SP, 1982). Professora Associada I da Universidade de Brasília (UnB) onde leciona no Curso de graduação em Arquivologia e no Programa de Pós-graduação em Ciência da Informação da Faculdade de Ciência da Informação (FCl). Temas de interesse sobre os quais tem publicado: Arquivos, Arquivologia, instituições arquivísticas e afins; Mediação cultural, comunicação e difusão de acervos; Políticas, legislação e outros dispositivos normativos e de controle da informação; Dimensões conceituais e tecnológicas do documento de arquivo; Informação e Memória.

medleg.georgete@gmail.com

Recebido - Received: 2015-09-30

Aceitado - Accepted: 2015-12-20

1 Disclosure, evidenciação e divulgação, no presente trabalho, são intercambiáveis e significam tornar algo evidente, público - no caso, as informações.

${ }^{2}$ Accountability - o termo não tem tradução literal para o idioma português, mas seu significado tem a ver com o conjunto de mecanismos e procedimentos que levam os dirigentes públicos a prestar contas de seus atos (MATIAS-PEREIRA, 2010a).

\section{(cc) $\mathrm{Br}$}

This work is licensed under a Creative Commons Attribution 4.0 United States License.

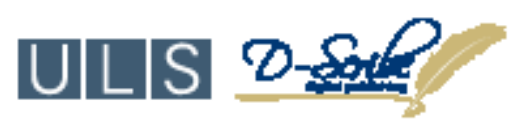

This journal is published by the University Library System of the University of Pittsburgh as part of its D-Scribe Digital Publishing Program and is cosponsored by the University of Pittsburgh Press. 